\title{
Farelo de Cacau (Theobroma cacao L.) e Torta de Dendê (Elaeis guineensis, Jacq) na Alimentação de Cabras em Lactação: Consumo e Produção de Leite ${ }^{1}$
}

\section{Herymá Giovane de Oliveira Silva², Aureliano José Vieira Pires ${ }^{3}$, Fabiano Ferreira da Silva ${ }^{3}$, Cristina Mattos Veloso ${ }^{3}$, Gleidson Giordano Pinto de Carvalho ${ }^{4}$, Andréia Santos Cezário ${ }^{5}$, Cibele Costa Santos ${ }^{6}$}

\begin{abstract}
RESUMO - Foram avaliados o consumo e a produção de leite de cabras recebendo dietas contendo farelo de cacau (FC) ou torta de dendê (TD) em substituição ao milho e ao farelo de soja da ração concentrada. Foram utilizadas cinco cabras da raça Saanen, com produção média diária de 2,0 kg de leite e aos 60 dias de lactação, distribuídas em um quadrado latino 5 x 5 . Os períodos experimentais tiveram duração de 14 dias, em que os dez primeiros foram destinados à adaptação e os quatro últimos, à coleta de amostras. As rações foram isoprotéicas, com 13,2\% de proteína bruta. As dietas constituíram-se de 36\% de volumoso (silagem de milho) e 64\% de concentrado na matéria seca. Os tratamentos consistiram de concentrado à base de milho e soja com 0, 15 e 30\% de FC ou TD. Os consumos de matéria seca, matéria orgânica, proteína bruta, nutrientes digestíveis totais, carboidratos totais e carboidratos não-fibrosos reduziram com a inclusão de 30\% de FC. Os consumos de fibra em detergente neutro e extrato etéreo (EE) não foram alterados pelas dietas. O consumo de fibra em detergente ácido diferiu apenas entre os tratamentos com 30\% de TD e 30\% de FC, sendo 0,94 e 0,59\% do peso vivo animal, respectivamente. O tratamento com 30\% de FC proporcionou menor produção de leite (1,208 kg/dia), se assemelhando apenas ao tratamento com inclusão de 30\% de TD quando a produção foi corrigida para 3,5\% de gordura. O FC e a TD apresentam viabilidade de uso como alternativa na dieta de cabras em lactação em até 9,13 e 18,81\% da matéria seca, respectivamente.
\end{abstract}

Palavras chave: caprino, subprodutos, leite de cabra

\section{Effects of Feeding Cocoa Meal (Theobroma cacao L.) and Palm Kernel Cake (Elaeis guineensis, Jacq) on Milk Intake and Yield for Lactating Goats}

\begin{abstract}
The effects of replacing corn and soybean meal with cocoa meal (CF) or palm kernel cake (PKC) in the concentrate on milk intake and yield of goats were evaluated. Five Saanen goats, averaging $2 \mathrm{~kg}$ daily milk yield at 60 days of lactation, were assigned to a 5 x 5 Latin square experimental design. The experiment lasted 14 days, with 10 days for adaptation period and four days for sample collection. Diets contained: $36 \%$ of roughage (corns silage) and $64 \%$ of concentrate, dry matter basis, formulated toyield $13.2 \%$ of crude protein. The treatments were as follows: 0, 15 and 30\% CF or PKC, all with concentrate (corn and soybean meal). Dry matter, organic matter, crude protein, total digestible nutrients, total carbohydrates and nonfiber carbohydrates intakes decreased as affected by the highest replacement level (30\% CF). No significant differences on neutral detergent fiber and ether extract intake were observed. Acid detergent fiber intake differed only between 30\% PKC and 30\% CF-based diets, with 0.94 and $0.59 \%$ body weight, respectively. The 30\% CFbased diet showed lower milk production value, as kg/dia (1.208 kg), but similar to 30\% PKC-based diet, when corrected for 3.5\% fat. Replacing corn and soybean with CF and PKC in the diet of lactating goats is viable up to 9.13 and $18.81 \%$ dry matter, respectively.
\end{abstract}

Key Words: goat, goat milk, by-products

\section{Introdução}

A alimentação dos animais representa o maior custo da atividade pecuária, sobretudo quando se utiliza fonte suplementar como o milho, que, apesar da elevada qualidade nutricional, apresenta, em geral, alto custo, tornando necessária a utilização de fontes alimentares alternativas com melhor relação custo/benefício e que não concorram diretamente com a alimentação humana.
Os subprodutos agroindustriais surgem como alternativa viável tanto nutricional como economicamente. Entre estes, encontram-se o farelo de cacau e a torta de dendê, abundantes nas regiões Norte e Nordeste do Brasil. O estado da Bahia é responsável por toda produção de cacau do Nordeste e por $69,9 \%$ da produção total brasileira. No Parque Industrial de Ilhéus, na Bahia, processam-se 450 toneladas de amêndoa seca de cacau, o que gera 45 toneladas

\footnotetext{
${ }^{1}$ Parte da dissertação de mestrado do primeiro autor, projeto financiado pela UESB.

2Professor Assistente do curso de Zootecnia, DTRA-UESB, Itapetinga-Bahia (heryma@uesb.br).

${ }^{3}$ Professor Adjunto do curso de Zootecnia, DTRA-UESB, Itapetinga-Bahia.

${ }^{4}$ Estudante do curso de Mestrado em Zootecnia - UFV.

${ }^{5}$ Estudante do curso de Zootecnia, UESB, Itapetinga-Bahia, Bolsista PIBIC/CNPq

${ }^{6}$ Estudante do curso de Zootecnia, UESB, Itapetinga-Bahia, Bolsista FAPESB.
} 
diárias de farelo (dados estimados nas quatro unidades processadoras no ano de 2003). Com base nessa relação e na produção de amêndoa seca de cacau de 196.788 toneladas no ano de 2000 (IBGE, 2004), estima-se que a produção brasileira de farelo de cacau foi de 19.678,8 t.

O farelo de cacau é o subproduto das amêndas, resultante da retirada da casca, após ser lavada, seca ao ar e submetida a vapor. Pode ser obtido ainda no processo de torrefação para produção de manteiga ou chocolate. É encontrado no mercado por preços mais acessíveis que outros alimentos comumente utilizados em concentrados para ruminantes.

Em experimento realizado com novilhas, Pires et al. (2005) verificaram que a adição de 0; 25 e 50\% de farelo de cacau (0; 10 e 20\% na MS da dieta) resultou em redução no consumo de MS para o tratamento com $50 \%$ de inclusão. Segundo esses autores, os consumos, conforme a ordem crescente de inclusão, foram, respectivamente, de 3,49; 3,31 e 2,8\%PV.

A torta de dendê é o produto resultante da polpa seca do dendê, após moagem e extração do óleo. A produção brasileira de dendê cresceu de 522.883 para 717.893 toneladas no período de 1990 a 2002, sendo o Norte e Nordeste as principais regiões produtoras (IBGE, 2004). Apesar do volume gerado, poucas são as informações científicas sobre o uso deste resíduo na alimentação de caprinos.

Silva et al. (2000), estudando níveis de substituição de 0; 25; 50 e 75\% do milho pela torta de dendê na alimentação de bezerros leiteiros, não observaram diferenças no consumo de MS na fase de aleitamento, registrando valores médios de $0,76 \mathrm{~kg} / \mathrm{dia}, 1,47 \%$ de PV e $39,33 \mathrm{~g} / \mathrm{kg} \mathrm{PV}^{0,75}$. Contudo, nos 60 dias após desmame, observaram redução linear no consumo de MS com o acréscimo de torta de dendê na dieta, o que pode ter sido decorrido da palatabilidade ou do teor de fibra deste subproduto, que apresenta 70\% de FDN.

A quantidade de alimento ingerido é fundamental, pois determina a disponibilidade de nutrientes para os processos fisiológicos do animal e, conseqüentemente, de seu desempenho. Conforme Van Soest (1994), sob dietas de baixa qualidade, vários fatores podem estar relacionados ao controle do consumo, entre eles: limitações no tempo de alimentação; “enchimento” e, conseqüentemente, limite da distensão ruminal; deficiências de nitrogênio; elevadas produções de ácido acético em dietas ricas em fibras; e carência de outros nutrientes envolvidos no mecanismo. Portanto, o con- trole envolve tanto fatores que retardam a digestão ruminal provocando "enchimento", como os que atuam mais diretamente no metabolismo animal.

Este trabalho foi desenvolvido objetivando-se avaliar a influência da utilização de farelo de cacau e de torta de dendê na alimentação de cabras leiteiras sobre o consumo de matéria seca , matéria orgânica, proteína bruta, proteína insolúvel em detergente neutro, nutrientes digestíveis totais, fibra em detergente neutro, fibra em detergente ácido, carboidratos totais, carboidratos não-fibrosos e extrato etéreo e a produção de leite.

\section{Material e Métodos}

O experimento foi realizado no Setor de Caprinocultura da Universidade Estadual do Sudoeste da Bahia - UESB, em Itapetinga, Bahia, no período de setembro a dezembro de 2002.

Foram utilizadas cinco cabras da raça Saanen, distribuídas em um quadrado latino 5 x 5, com períodos de 14 dias de duração cada, sendo os dez primeiros dias para adaptação e os quatro finais, para coleta de amostras. As cabras apresentavam, em média, 41,66 $\mathrm{kg}$ de peso vivo, $2 \mathrm{~kg}$ de leite por dia e 60 dias de lactação e foram alojadas em baias de 1,2 x 2,1 m $\left(2,52 \mathrm{~m}^{2}\right)$, com piso ripado de madeira, com acesso a bebedouro e comedouro individuais.

As cabras tiveram livre acesso à água e foram alimentadas ad libitum duas vezes ao dia, às $8 \mathrm{~h}$ e $15 \mathrm{~h} 30$, com dietas balanceadas, isoprotéicas, contendo 13,2\% de $P B$, de forma a atenderem às exigências de mantença e lactação para produção de $2 \mathrm{~kg}$ de leite/dia, como preconizado pelo NRC (1981). O volumoso utilizado foi silagem de milho, na proporção de 36\% na MS para todos os tratamentos, e o concentrado consistiu de três níveis (0; 15 e 30\%) de inclusão de farelo de cacau ou de torta de dendê em substituição ao milho e farelo de soja, conforme os seguintes tratamentos:

T1 = Silagem de milho + concentrado padrão;

$\mathrm{T} 2=$ Silagem de milho + concentrado com $15 \%$ de farelo de cacau;

T3 = Silagem de milho + concentrado com $30 \%$ de farelo de cacau;

$\mathrm{T} 4=$ Silagem de milho + concentrado com $15 \%$ de torta de dendê; e

T5 =Silagem de milho + concentrado com $30 \%$ de torta de dendê.

A composição dos alimentos se encontra na Tabela 1 e a das dietas, na Tabela 2 . 
Tabela 1 - Composição química dos ingredientes Table 1 - Chemical composition of the ingredients

\begin{tabular}{|c|c|c|c|c|c|}
\hline $\begin{array}{l}\text { Nutriente (\%) } \\
\text { Nutrient }\end{array}$ & $\begin{array}{l}\text { Milho } \\
\text { Corn }\end{array}$ & $\begin{array}{l}\text { Farelo de soja } \\
\text { Soybean meal }\end{array}$ & $\begin{array}{c}\text { Farelo de cacau } \\
\text { Cocoa meal }\end{array}$ & $\begin{array}{l}\text { Torta de dendê } \\
\text { Palm kenel cake }\end{array}$ & $\begin{array}{l}\text { Silagem de milho } \\
\text { Corn silage }\end{array}$ \\
\hline $\begin{array}{l}\text { MS } \\
D M\end{array}$ & 86,86 & 86,31 & 86,14 & 88,38 & 27,01 \\
\hline $\begin{array}{l}\mathrm{MO} \\
\mathrm{OM}\end{array}$ & 98,92 & 93,55 & 92,64 & 95,57 & 90,04 \\
\hline $\begin{array}{l}\mathrm{PB} \\
C P\end{array}$ & 8,59 & 47,35 & 13,62 & 14,51 & 7,81 \\
\hline $\begin{array}{l}\mathrm{EE} \\
\mathrm{EE}\end{array}$ & 5,08 & 3,26 & 11,09 & 7,19 & 2,27 \\
\hline $\begin{array}{l}\text { FDN } \\
N D F\end{array}$ & 11,53 & 13,36 & 45,56 & 81,85 & 71,84 \\
\hline $\begin{array}{l}\text { FDA } \\
A D F\end{array}$ & 2,23 & 7,64 & 37,81 & 42,30 & 33,05 \\
\hline $\begin{array}{l}\text { CT } \\
\text { TC }\end{array}$ & 85,25 & 42,94 & 67,93 & 73,86 & 78,62 \\
\hline $\begin{array}{l}\mathrm{CNF} \\
N F C\end{array}$ & 86,72 & 37,10 & 35,29 & 1,53 & 19,66 \\
\hline $\begin{array}{l}* \text { PIDN } \\
\text { NDIP }\end{array}$ & 16,41 & 4,45 & 52,20 & 49,43 & 19,46 \\
\hline $\begin{array}{l}\text { MM } \\
\text { Ash }\end{array}$ & 1,08 & 6,45 & 7,36 & 4,43 & 9,96 \\
\hline
\end{tabular}

* Percentual da proteína bruta (Crude protein percentage).

$\mathrm{MS}$ = matéria seca; $\mathrm{MO}$ = matéria orgânica; $\mathrm{PB}$ = proteína bruta; $\mathrm{EE}=$ extrato etéreo; FDN = fibra em detergente neutro; FDA = fibra em detergente ácido; $\mathrm{CT}$ = carboidratos totais; $\mathrm{CNF}$ = carboidratos não-fibrosos; $\mathrm{PIDN}$ = proteína insolúvel em detergente neutro; $\mathrm{MM}=$ matéria mineral.

$D M=$ dry matter; $O M=$ organic matter $; C P=$ crude protein; $E E=$ ether extract; $N D F=$ neutral detergent fiber; $A D F=$ acid detergent fiber; $T C=$ total $c a r b o h y d r a t e s$, $N F C=$ nonfiber carbohydrates; NDIP = neutral detergent insoluble protein; $M M=$ mineral mix.

As amostras dos alimentos, das sobras e fezes foram coletadas diariamente, congeladas, homogeneizadas e pré-secas em estufa a $65^{\circ} \mathrm{C}$ por 72 horas. Todas as amostras foram trituradas em moinho dotado de peneira com crivos de $1 \mathrm{~mm}$ de diâmetro e armazenadas, para posterior análise dos teores de matéria seca (MS), matéria orgânica (MO), proteína bruta (PB), extrato etéreo (EE), fibra em detergente neutro (FDN) e fibra em detergente ácido (FDA), de acordo com as metodologias descritas por Silva \& Queiroz (2002). Os carboidratos totais (CT) foram obtidos segundo Sniffen et al. (1992), em que: os carboidratos fibrosos (CF) correspondem à FDN corrigida para o seu conteúdo em matéria mineral e proteína(FDNmp) e os carboidratos não-fibrosos (CNF) são obtidos pela subtração da FDNmp dos carboidratos totais (CT): $\mathrm{CT}=100-(\% \mathrm{~PB}+\% \mathrm{EE}+\% \mathrm{MM})$; $\mathrm{CNF}=100-(\mathrm{PB} \%+\mathrm{FDNpm} \%+\mathrm{EE} \%+\mathrm{MM} \%)$

Os teores de nutrientes digestíveis totais (NDT) foram calculados pelo somatório da proteína bruta digestível (PBD), da fibra em detergente neutro digestível (FDND), do extrato etéreo digestível (EED) multiplicado por 2,25. Os teores de carboidratos não-fibrosos digestíveis (CNFD), por sua vez, foram estimados segundo Weiss (1999).

$$
\mathrm{NDT}=\mathrm{PBD}+2,25 \times \mathrm{EED}+\mathrm{CNFD}+\mathrm{FDND}
$$

A energia digestível (ED) foi calculada pela expressão: $\mathrm{ED}=\mathrm{NDT} \times 4,409$ Mcal e a energia metabolizável $(\mathrm{EM})=\mathrm{ED} \times 0,82$.

A pesagem do leite foi realizada diariamente, mas entre o $11^{\circ}$ e $14^{\circ}$ dias, a produção foi utilizada para avaliação das dietas. A produção de leite corrigida para 3,5\% de gordura foi calculada segundo Sklan et al. (1992): PLC $=(0,432+0,11625 \mathrm{x} \%$ de gordura do leite) x produção de leite em $\mathrm{kg} /$ dia.

Os resultados foram analisados estatisticamente por análise de variância e pelo teste Tukey a 5\%, utilizando-se o Sistema de Análises Estatísticos e Genéticos - SAEG (UFV, 1998). 
Tabela 2 - Composição das dietas $(\%)^{1}$ Table 2 - Diet composition (\%)

\begin{tabular}{|c|c|c|c|c|c|}
\hline \multirow[b]{2}{*}{$\begin{array}{l}\text { Alimento (\%) } \\
\text { Feed }\end{array}$} & \multicolumn{4}{|c|}{$\begin{array}{c}\text { Tratamento } \\
\text { Treatment }\end{array}$} & \multirow[b]{2}{*}{$\begin{array}{l}\text { 30\% de torta } \\
\text { de dendê } \\
\text { 30\% palm kerne } \\
\text { cake }\end{array}$} \\
\hline & $\begin{array}{c}\text { Controle } \\
\text { Control }\end{array}$ & $\begin{array}{l}15 \% \text { de farelo } \\
\text { de cacau } \\
15 \% \text { cocoa meal }\end{array}$ & $\begin{array}{l}30 \% \text { de farelo } \\
\text { de cacau } \\
30 \% \text { cocoa meal }\end{array}$ & $\begin{array}{c}\text { 15\% de torta } \\
\text { de dendê } \\
\text { 15\% palm kernel } \\
\text { cake }\end{array}$ & \\
\hline $\begin{array}{l}\text { Silagem de milho } \\
\text { Corn silage }\end{array}$ & 36,00 & 36,00 & 36,00 & 36,00 & 36,00 \\
\hline $\begin{array}{l}\text { Milho moído } \\
\text { Ground corn }\end{array}$ & 47,58 & 39,38 & 31,35 & 39,54 & 31,43 \\
\hline $\begin{array}{l}\text { Farelo de soja } \\
\text { Soybean meal }\end{array}$ & 14,30 & 13,25 & 12,03 & 12,89 & 11,63 \\
\hline $\begin{array}{l}\text { Farelo de cacau } \\
\text { Cocoa meal }\end{array}$ & 0,00 & 9,23 & 18,47 & 0,00 & 0,00 \\
\hline $\begin{array}{l}\text { Torta de dendê } \\
\text { Palm kernel cake }\end{array}$ & 0,00 & 0,00 & 0,00 & 9,43 & 18,81 \\
\hline $\begin{array}{l}\text { Mistura mineral } \\
\text { Mineral mixture } \\
\text { Nutrientes no con } \\
\text { Concentrate nutrie }\end{array}$ & 2,12 & 2,14 & 2,14 & 2,13 & 2,13 \\
\hline $\mathrm{PB}(C P)$ & 16,65 & 16,63 & 16,40 & 16,21 & 16,37 \\
\hline $\mathrm{EE}(E E)$ & 3,43 & 3,91 & 5,31 & 4,01 & 3,82 \\
\hline FDN (NDF) & 19,44 & 22,24 & 27,05 & 28,99 & 31,01 \\
\hline FDA (ADF) & 7,06 & 8,28 & 12,52 & 10,81 & 17,35 \\
\hline $\mathrm{CT}(\mathrm{TC})$ & 74,90 & 73,69 & 72,06 & 76,63 & 74,23 \\
\hline CNF (NFC) & 58,00 & 55,03 & 50,45 & 50,63 & 47,44 \\
\hline $\begin{array}{l}\text { *PIDN (NDIP) } \\
\text { Nutrientes na diet }\end{array}$ & 9,65 & 15,53 & 25,28 & 17,68 & 20,38 \\
\hline $\mathrm{PB}(C P)$ & 13,20 & 13,31 & 13,28 & 13,40 & 13,58 \\
\hline $\mathrm{EE}(E E)$ & 3,49 & 3,81 & 4,72 & 3,87 & 3,76 \\
\hline FDN (NDF) & 35,63 & 37,65 & 40,86 & 41,99 & 43,42 \\
\hline FDA (ADF) & 16,10 & 16,99 & 19,78 & 18,6 & 22,97 \\
\hline $\mathrm{CT}(\mathrm{TC})$ & 76,18 & 75,40 & 74,34 & 77,32 & 75,74 \\
\hline CNF (NFC) & 44,87 & 42,77 & 39,72 & 39,96 & 37,76 \\
\hline *PIDN (NDIP) & 13,03 & 16,88 & 23,26 & 18,31 & 20,06 \\
\hline
\end{tabular}

${ }^{1}$ Base na matéria seca (Dry matter basis).

* Percentual da proteína bruta (Crude protein percentage).

$\mathrm{PB}=$ proteína bruta; $\mathrm{EE}=$ extrato etéreo; FDN = fibra em detergente neutro; FDA= fibra em detergente ácido; $\mathrm{CT}=\mathrm{carboidratos}$ totais; CNF = carboidratos não-fibrosos; PIDN = proteína insolúvel em detergente neutro.

$C P=$ crude protein $; E E=$ ether extract $; N F=$ neutral detergent fiber; $A D F=$ acid detergent fiber; $T C=$ total carbohydrates, NFC = nonfiber carbohydrates; NDIP = neutral detergent insoluble protein.

\section{Resultados e Discussão}

Os resultados dos consumos médios diários de MS e de MO pelas cabras leiteiras que receberam dietas com diferentes níveis de inclusão de farelo de cacau ou torta de dendê são apresentados na Tabela 3. Os níveis de ingestão de MS total por unidade de peso metabólico observados neste trabalho (Tabela 3) foram superiores aos obtidos por Silva et al. (1999), de 99,31 a 102,03 g/kg PV ${ }^{0,75} \cdot \mathrm{d}^{-1}$ de MS, em cabras produzindo 1,80 a $2,12 \mathrm{~kg} /$ dia. Esses valores elevados podem ser explicados pelo alto teor de concentrado nas dietas, o que diminuiu o consumo de FDN, aumen- tando a taxa de passagem da digesta. Ao avaliarem os sistemas NRC (1981) e AFRC (1993) para caprinos, Carvalho et al. (2002) utilizaram níveis de 20; 27; 34; 41 e 48\% de FDN da forragem na alimentação de cabras leiteiras e constataram que apenas o nível com menor teor de FDN proporcionou consumo de MS próximo ao predito pelo NRC (1981). Para os demais, o consumo de MS predito foi maior em 7\% que os observados. Gonçalves et al. (2001) observaram que cabras que ingerem exclusivamente volumoso chegam a consumir 2,5 vezes mais que bovinos (em percentuais de PV) e atribuíram o fato à maior taxa de passagem observada em caprinos. 
O consumo de dietas contendo 15 e $30 \%$ de torta de dendê, expresso em kg/dia, \% PV e em gramas por unidade de tamanho metabólico, não diferenciou $(\mathrm{P}>0,05)$ da dieta padrão à base de milho e soja. No entanto, com a inclusão de $30 \%$ de farelo de cacau, o consumo foi inferior $(\mathrm{P}<0,05)$ para todas as variáveis estudadas. Rodrigues Filho et al. (1996) verificaram redução no consumo de MS em ovelhas alimentadas com 29,7\% da MS de torta de dendê na dieta total em substituição ao farelo de trigo. Entretanto, quando os teores foram de $17,8 \%$ da MS total da dieta, os resultados foram semelhantes àqueles encontrados neste trabalho, em que níveis de inclusão de torta de dendê de $18,81 \%$ da MS total da dieta não afetaram o consumo de MS em cabras leiteiras.

Comparando os valores para consumo de MS preconizados pela AFRC (1993), para cabras com 50 kg de PV e produção de leite de $2 \mathrm{~kg} /$ dia $(1,78 \mathrm{~kg} / \mathrm{dia}$ de MS), com os obtidos neste trabalho, observa-se que apenas o tratamento com 30\% de inclusão de farelo de cacau foi inferior, sendo menor em $15,67 \%$. O menor consumo observado nesse tratamento decorreu da seleção do volumoso pelas cabras em detrimento ao concentrado. Essa seleção foi facilitada pelas diferenças físicas de densidade e tamanho, de modo que o concentrado acumulava-se no fundo do cocho.
Com o aumento no consumo do volumoso em relação ao do concentrado, o mecanismo de controle da ingestão, no tratamento com $30 \%$ de $\mathrm{FC}$, poderia ter ocorrido pelo “enchimento” e, conseqüentemente, pelo limite da distensão do retículo-rúmen. No entanto, visto que não houve diferenças $(\mathrm{P}>0,05)$ nos teores e no coeficiente de digestibilidade aparente da proteína consumida, no consumo de FDN e na densidade calórica da dieta, outros fatores como palatabilidade ou agentes antinutricionais podem ter agido como limitantes.

A proteína parece ser um dos nutrientes mais importantes na alimentação de cabras (Silva Sobrinho et al., 1991) e pode afetar o consumo (Lizieire et al., 1990). A concentração e a qualidade da proteína na dieta podem afetar o consumo pelos ruminantes, alterando tanto o mecanismo físico como o fisiológico. No entanto, neste estudo, o nível de proteína da dieta consumida não influenciou a ingestão de MS, pois seus teores foram semelhantes $(\mathrm{P}>0,05)$ e estão acima de 7\%, valor mínimo recomendado para fermentação microbiana (Van Soest, 1994).

Os consumos médios de PB registrados na Tabela 4 foram superiores aos valores recomendados pelo NRC (1981), de $227 \mathrm{~g} /$ dia para cabras com $50 \mathrm{~kg}$ de $\mathrm{PV}$, submetidas à atividade reduzida e produzindo $2 \mathrm{~kg}$ de leite com 3,5\% de gordura, exceto para o tratamento

Tabela 3 - Consumo, em gramas por dia (g/dia), porcentagem do peso vivo (\%PV) e em função do peso metabólico (PM), de matéria seca (MS) e matéria orgânica (MO) por cabras Saanen alimentadas com dietas contendo diferentes níveis de inclusão de farelo de cacau (FC) ou torta de dendê (TD)

Table 3 - Intake, expressed as grams/day (g/day), as body weight percentage (\% LW) and as metabolic weight (MW) of dry matter (DM) and organic matter (OM) for Saanen goats fed increasing levels of cocoa meal (FC) or palm kernel cake (TD)

\begin{tabular}{|c|c|c|c|c|c|c|c|}
\hline \multirow[t]{2}{*}{$\begin{array}{l}\text { Variável } \\
\text { Trait }\end{array}$} & \multicolumn{5}{|c|}{$\begin{array}{c}\text { Tratamento* } \\
\text { Treatment* }\end{array}$} & \multirow[t]{2}{*}{$\begin{array}{l}\text { Média } \\
\text { Mean }\end{array}$} & \multirow[t]{2}{*}{$\mathrm{CV}(\%)$} \\
\hline & $\begin{array}{c}\text { Controle } \\
\text { Control }\end{array}$ & $\begin{array}{l}15 \% \mathrm{FC} \\
15 \% \mathrm{FC}\end{array}$ & $\begin{array}{l}30 \% \mathrm{FC} \\
30 \% \mathrm{FC}\end{array}$ & $\begin{array}{l}15 \% \text { TD } \\
15 \% \text { TD }\end{array}$ & $\begin{array}{l}30 \% \text { TD } \\
30 \% \text { TD }\end{array}$ & & \\
\hline $\begin{array}{l}\text { MS (kg/dia) } \\
\text { DM (kg/day) }\end{array}$ & $2,222 \mathrm{a}$ & $2,245 \mathrm{a}$ & 1,501b & $2,132 \mathrm{a}$ & $2,209 a$ & 2,062 & 13,87 \\
\hline $\begin{array}{l}\mathrm{MS}(\% \mathrm{PV}) \\
D M(\% L W)\end{array}$ & $4,46 \mathrm{a}$ & $4,46 \mathrm{a}$ & $3,08 b$ & $4,31 \mathrm{a}$ & $4,49 \mathrm{a}$ & 4,16 & 12,38 \\
\hline $\begin{array}{l}\mathrm{MS}(\mathrm{g} / \mathrm{PM}) \\
D M(g / M W)\end{array}$ & 118,37 a & $118,82 \mathrm{a}$ & $81,31 b$ & $114,31 \mathrm{a}$ & 118,87 a & 110,30 & 12,69 \\
\hline $\begin{array}{l}\text { MO (kg/dia) } \\
\text { OM (kg/day) }\end{array}$ & $2,084 \mathrm{a}$ & $2,098 \mathrm{a}$ & 1,399b & $2,004 \mathrm{a}$ & $2,235 a$ & 1,929 & 13,61 \\
\hline $\begin{array}{l}\mathrm{MO}(\% \mathrm{PV}) \\
\mathrm{OM}(\% L W)\end{array}$ & $4,18 \mathrm{a}$ & $4,17 \mathrm{a}$ & $2,87 b$ & $4,05 \mathrm{a}$ & $4,19 \mathrm{a}$ & 3,89 & 12,12 \\
\hline
\end{tabular}

Médias seguidas de mesma letra na linha não diferiram entre si pelo teste Tukey a $5 \%$.

* \% de FC ou TD no concentrado em uma relação v:c de 36:64\%.

Means followed by the same letter in a row did not differ by Tukey test at 5\%.

* FC or TD\% in the concentrate, using roughage:concentrate ration of 36:64\%. 
com $30 \%$ de inclusão de farelo de cacau, no qual o consumo foi $20,4 \%$ inferior ao recomendado.

Como as dietas foram formuladas para serem isoprotéicas, a redução verificada no consumo de MS pode ser considerada a responsável pela redução da ingestão de proteína bruta nos tratamentos contendo FC. No entanto, esperava-se também redução no consumo de PB para as dietas contendo torta de dendê (15 e 30\%), o que não ocorreu.

Os teores de proteína insolúvel em detergente neutro para as dietas com $30 \%$ de farelo de cacau foram superiores aos dos tratamentos controle e com
$15 \%$ de farelo de cacau, e o tratamento com $30 \%$ de inclusão de torta de dendê foi superior $(\mathrm{P}<0,05)$ ao tratamento controle.

Considerando-se as recomendações do NRC (1981), de 4,37 Mcal/dia de EM/dia para uma cabra com $50 \mathrm{~kg}$ de PV, produzindo 2,0 kg/dia, com 3,5\% de gordura, apenas o tratamento com $30 \%$ de farelo de cacau não satisfez às recomendações para essa associação. Em decorrência da redução do teor de NDT nas dietas com o aumento da participação do volumoso, esperava-se que os teores de nutrientes digestíveis totais da dieta consumida com $30 \%$ de

Tabela 4 - Consumo de proteína bruta (PB), proteína insolúvel em detergente neutro (PIDN), nutrientes digestíveis totais (NDT), energia digestível (ED), fibra em detergente neutro (FDN) e fibra em detergente ácido (FDA) por cabras Saanen alimentadas com dietas contendo diferentes níveis de inclusão de farelo de cacau (FC) ou torta de dendê (TD)

Table 4 - Intake of crude protein (CP), neutral detergent insoluble protein (NDIP), total digestible nutrients (TDN), digestible energy $(D E)$, neutral detergent fiber (NDF) and acid detergent fiber (ADF) of Saanen goats fed increasing levels of cocoa meal (FC) or palm kernel cake (TD)

\begin{tabular}{|c|c|c|c|c|c|c|c|}
\hline \multirow[t]{2}{*}{$\begin{array}{l}\text { Variável } \\
\text { Trait }\end{array}$} & \multicolumn{5}{|c|}{$\begin{array}{c}\text { Tratamento* } \\
\text { Treatment* }\end{array}$} & \multirow[t]{2}{*}{$\begin{array}{l}\text { Média } \\
\text { Mean }\end{array}$} & \multirow[t]{2}{*}{ CV $(\%)$} \\
\hline & $\begin{array}{l}\text { Controle } \\
\text { Control }\end{array}$ & $\begin{array}{l}15 \% \mathrm{FC} \\
15 \% \mathrm{FC}\end{array}$ & $\begin{array}{l}30 \% \mathrm{FC} \\
30 \% \mathrm{FC}\end{array}$ & $\begin{array}{l}15 \% \mathrm{TD} \\
15 \% \mathrm{TD}\end{array}$ & $\begin{array}{l}30 \% \text { TD } \\
30 \% \text { TD }\end{array}$ & & \\
\hline $\begin{array}{l}\text { PB (g/dia) } \\
C P \text { (g/day) }\end{array}$ & 293,96a & 299,91 a & $180,68 b$ & $238,47 a b$ & 283,92ab & 259,39 & 20,52 \\
\hline $\begin{array}{l}\mathrm{PB}(\% \mathrm{PV}) \\
C P(g / L W)\end{array}$ & $0,60 \mathrm{a}$ & 0,59 a & $0,37 b$ & $0,48 a b$ & $0,59 \mathrm{ab}$ & 0,52 & 19,69 \\
\hline $\begin{array}{l}\mathrm{PB}(\mathrm{g} / \mathrm{PM}) \\
C P(g / M W)\end{array}$ & $16,02 \mathrm{a}$ & 15,58 a & $9,80 \mathrm{~b}$ & $12,77 \mathrm{ab}$ & $15,30 \mathrm{ab}$ & 13,85 & 19,84 \\
\hline $\begin{array}{l}\text { PIDN (\%) } \\
\text { NDIP (\%) }\end{array}$ & $9,65 c$ & 14,29 bc & 25,28 a & 17,68 abc & $20,38 \mathrm{ab}$ & 17,45 & 26,53 \\
\hline $\begin{array}{l}\text { NDT (kg/dia) } \\
\text { TDN (kg/day) }\end{array}$ & $1,47 \mathrm{a}$ & 1,35 a & $0,87 \mathrm{~b}$ & $1,30 \mathrm{ab}$ & $1,37 \mathrm{a}$ & 1,27 & 17,99 \\
\hline $\begin{array}{l}\text { NDT (\%PV) } \\
T D N(\% L W)\end{array}$ & $2,95 \mathrm{a}$ & $2,68 \mathrm{a}$ & $1,79 \mathrm{~b}$ & 2,62 ab & $2,79 \mathrm{a}$ & 2,57 & 16,36 \\
\hline $\begin{array}{l}\text { NDT(g/PM) } \\
T D N(g / M W)\end{array}$ & $78,32 \mathrm{a}$ & $71,29 a$ & $47,28 b$ & $69,50 \mathrm{ab}$ & 73,83 a & 68,04 & 16,72 \\
\hline $\begin{array}{l}\text { ED(Mcal/dia) } \\
\text { DE (Mcal/day) }\end{array}$ & $6,46 \mathrm{a}$ & $5,94 \mathrm{a}$ & $3,83 \mathrm{~b}$ & 5,71 ab & $6,05 \mathrm{a}$ & 5,60 & 17,98 \\
\hline $\begin{array}{l}\text { FDN (g/dia) } \\
N D F \text { (g/day) }\end{array}$ & 722,40 a & $757,58 a$ & $608,34 \mathrm{a}$ & 787,83a & $876,18 a$ & 750,47 & 19,96 \\
\hline $\begin{array}{l}\text { FDN (\%PV) } \\
N D F(\% L W)\end{array}$ & $1,45 \mathrm{a}$ & $1,51 \mathrm{a}$ & $1,25 \mathrm{a}$ & $1,60 \mathrm{a}$ & $1,77 \mathrm{a}$ & 1,52 & 18,20 \\
\hline $\begin{array}{l}\mathrm{FDN}(\mathrm{g} / \mathrm{PM}) \\
N D F(g / L W)\end{array}$ & 38,57 a & 40,13 a & 33,08 a & $42,39 a$ & 46,96 a & 40,23 & 18,60 \\
\hline $\begin{array}{l}\text { FDA (g/dia) } \\
\text { ADF (g/day) }\end{array}$ & 323,43ab & $330,59 \mathrm{ab}$ & $287,20 b$ & 338,35 ab & 464,38 a & 348,79 & 22,38 \\
\hline $\begin{array}{l}\text { FDA (\%PV) } \\
A D F(\% L W)\end{array}$ & $0,64 b$ & $0,66 \mathrm{ab}$ & $0,59 \mathrm{~b}$ & $0,68 \mathrm{ab}$ & $0,94 \mathrm{a}$ & 0,70 & 20,40 \\
\hline $\begin{array}{l}\text { FDA (g/PM) } \\
A D F(g / M W)\end{array}$ & $17,02 \mathrm{~b}$ & 17,48 ab & $15,59 \mathrm{~b}$ & $18,15 \mathrm{ab}$ & 24,95 a & 18,64 & 20,84 \\
\hline
\end{tabular}

Médias seguidas de mesma letra na linha não diferiram entre si pelo teste Tukey a $5 \%$.

* \% de FC ou TD no concentrado em uma relação v:c de 36:64\%.

Means followed by the same letter in a row did not differ by Tukey test at $5 \%$.

${ }^{*} F C$ or TD\% in the concentrate, using roughage:concentrate ratio of $36: 64 \%$. 
farelo de cacau fossem inferiores aos demais, o que não ocorreu. O elevado teor de gordura dessa dieta pode ter contribuído para aproximar os resultados.

Os níveis de energia digestível das dietas consumidas (2,55 a 2,91 Mcal/kg de MS) não foram suficientes para provocar alterações no consumo de MS entre as diferentes dietas, provavelmente, em função da semelhança $(\mathrm{P}>0,05)$ na relação PB/NDT entre os tratamentos. Silva et al. (1996) não evidenciaram, em cabras em lactação, diferença no consumo de dietas com 12,54; 13,54 e 15,63\% de PB, associadas a níveis de 2,85; 2,97 e 3,20 Mcal de ED/kg de MS, respectivamente.

A utilização dos subprodutos elevou os teores de FDN nas dietas (Tabela 2), que foram maiores naquelas com inclusão da torta de dendê, no entanto, não houve diferenças na ingestão de FDN entre as rações (Tabela 4). As diferenças $(\mathrm{P}<0,05)$ no consumo de FDA entre os tratamentos com 30\% de farelo de cacau e 30\% de torta de dendê ocorreram em função do menor consumo de MS do tratamento com $30 \%$ de farelo de cacau.
Os consumos de carboidratos totais (CT), carboidratos não-fibrosos (CNF) e extrato etéreo (EE) foram influenciados pelo consumo de MS, podendo ser considerados altos, o que é justificável pela elevada proporção de concentrado nas dietas. Esperava-se diferença na ingestão de EE entre os tratamentos, em virtude da redução do consumo da ração com 30\% de farelo de cacau e dos menores teores de gordura no volumoso, visto que as cabras diminuíram o consumo do concentrado. Todavia, parece que as diferenças nos teores de EE das dietas consumidas foram suficientes para aproximar os resultados.

Os teores de EE obtidos nas dietas com 30\% farelo de cacau (Tabela 2) podem ter agido como elemento antinutricional, contribuindo para redução do consumo neste tratamento (Chalupa \& Ferguson, 1988). Essa influência negativa é atribuída à presença de ácidos graxos livres, à capacidade de formar sais insolúveis e à propriedade de formar barreira física sobre o alimento, dificultando a colonização microbiana (Palmquist, 1989). Oliveira Jr. (2000a) observou re-

Tabela 5 - Consumo de carboidratos totais (CT), carboidratos não-fibrosos (CNF) e extrato etéreo (EE) por cabras Saanen alimentadas com dietas contendo diferentes níveis de inclusão de farelo de cacau (FC) ou torta de dendê (TD)

Table 5 - Intake of total carbohydrates (TCH), nonfiber carbohydrates (NFC) and ether extract (EE) of Saanen goats fed increasing levels of cocoa meal (FC) or palm kernel cake (TD)

\begin{tabular}{|c|c|c|c|c|c|c|c|}
\hline \multirow[t]{2}{*}{$\begin{array}{l}\text { Variável } \\
\text { Trait }\end{array}$} & \multicolumn{5}{|c|}{$\begin{array}{c}\text { Tratamento* } \\
\text { Treatment* }\end{array}$} & \multirow[t]{2}{*}{$\begin{array}{l}\text { Média } \\
\text { Mean }\end{array}$} & \multirow[t]{2}{*}{ CV $(\%)$} \\
\hline & $\begin{array}{c}\text { Controle } \\
\text { Control }\end{array}$ & $\begin{array}{l}15 \% \mathrm{FC} \\
15 \% \mathrm{FC}\end{array}$ & $\begin{array}{l}30 \% \mathrm{FC} \\
30 \% \text { FC }\end{array}$ & $\begin{array}{l}15 \% \mathrm{TD} \\
15 \% \mathrm{TD}\end{array}$ & $\begin{array}{l}30 \% \text { TD } \\
30 \% \text { TD }\end{array}$ & & \\
\hline $\begin{array}{l}\text { CT (g/dia) } \\
\text { TC (g/day) }\end{array}$ & 1630 a & 1587 a & $1056 \mathrm{~b}$ & $1529 a b$ & 1583 a & 1476 & 16,20 \\
\hline $\begin{array}{l}\mathrm{CT}(\% \mathrm{PV}) \\
\mathrm{TC}(\% L W)\end{array}$ & $3,28 \mathrm{a}$ & 3,16 a & $2,17 b$ & 3,10 a & $3,22 \mathrm{a}$ & 2,99 & 14,65 \\
\hline $\begin{array}{l}\text { CT (g/PM) } \\
\text { TC }(g / M W)\end{array}$ & 87,12 a & 84,01 a & $57,33 b$ & 82,08 a & 85,18 a & 79,14 & 14,98 \\
\hline $\begin{array}{l}\text { CNF (kg/dia) } \\
\text { NFC (kg/day) }\end{array}$ & $1,000 \mathrm{a}$ & 0,936a & $0,537 b$ & $0,830 \mathrm{a}$ & 0,823 a & 0,825 & 16,19 \\
\hline $\begin{array}{l}\mathrm{CNF}(\% \mathrm{PV}) \\
N F C(\% L W)\end{array}$ & $2,02 \mathrm{a}$ & $1,86 \mathrm{a}$ & $1,10 \mathrm{~b}$ & $1,68 \mathrm{a}$ & 1,69 а & 1,67 & 15,55 \\
\hline $\begin{array}{l}\mathrm{CNF}(\mathrm{g} / \mathrm{PM}) \\
N F C(\mathrm{~g} / \mathrm{MW})\end{array}$ & 53,50 a & 49,53 a & $29,13 b$ & $44,48 \mathrm{a}$ & 44,53 a & 44,23 & 15,63 \\
\hline $\begin{array}{l}\mathrm{EE} \text { (g/dia) } \\
E E \text { (g/day) }\end{array}$ & 77,30 a & 81,06 a & 69,99 a & $80,42 \mathrm{a}$ & 81,23 a & 78,00 & 22,79 \\
\hline $\begin{array}{l}\mathrm{EE}(\% \mathrm{PV}) \\
E E(\% L W)\end{array}$ & $0,16 \mathrm{a}$ & $0,16 \mathrm{a}$ & $0,14 \mathrm{a}$ & $0,16 \mathrm{a}$ & 0,17 a & 0,16 & 22,61 \\
\hline $\begin{array}{l}\mathrm{EE}(\mathrm{g} / \mathrm{PM}) \\
E E(g / M W)\end{array}$ & $4,17 \mathrm{a}$ & $4,26 \mathrm{a}$ & $3,81 \mathrm{a}$ & $4,32 \mathrm{a}$ & $4,40 \mathrm{a}$ & 4,19 & 22,62 \\
\hline
\end{tabular}

Médias seguidas de mesma letra na linha não diferiram entre si pelo teste Tukey a 5\%.

* \% de FC ou TD no concentrado em uma relação v:c de 36:64\%.

Means followed by the same letter in a row did not differ by Tukey test at $5 \%$.

* FC or TD\% in the concentrate, using roughage:concentrate ratio of $36: 64 \%$. 
dução linear no consumo de MS com o aumento de EE $(3,2 ; 4,4 ; 5,6$ e $6,3 \%)$ na deita total proveniente da soja em grão, em função da redução na digestibilidade da fibra. Também Solaiman et al. (2002) evidenciaram redução no consumo de MS de cabras alimentadas com níveis crescentes de extrato etéreo $(4,5 ; 7,65$; 8,45 e $13,1 \%$ ) na dieta.

Os resultados das produções de leite e de leite corrigida para gordura das cabras recebendo dietas com diferentes níveis de inclusão de farelo de cacau ou torta de dendê são apresentados na Tabela 6 .
A produção média de leite observada de 1,630 kg/ dia se assemelha aos valores obtidos com cabras Saanen no Brasil. A utilização de torta de dendê em substituição ao milho e ao farelo de soja, dentro dos percentuais estudados, não afetou a produção de leite $(\mathrm{P}>0,05)$. Em função dos altos teores de FDN deste subproduto (Tabela 1), esperava-se menor produção com a inclusão de $30 \%$ de torta de dendê (19,2\% na MS da dieta total). No entanto, as produções foram de 1,759; 1,738 e 1,682 kg/dia, para os tratamentos com 0; 15 e 30\% de substituição com torta de dendê, respectivamente.

Tabela 6 - Produção de leite diária (PL) e produção de leite corrigida para gordura (PLC) de cabras Saanen alimentadas com dientas contendo diferentes níveis de inclusão de farelo de cacau (FC) ou torta de dendê (TD)

Table 6 - Daily milk yield (MP) and fat corrected milk yield (FCMP) of Saanen goats fed increasing levels of cocoa meal (FC) or palm kernel cake (TD)

\begin{tabular}{|c|c|c|c|c|c|c|c|}
\hline \multirow[t]{2}{*}{$\begin{array}{l}\text { Variável } \\
\text { Trait }\end{array}$} & \multicolumn{5}{|c|}{$\begin{array}{c}\text { Tratamento* } \\
\text { Treatment* }\end{array}$} & \multirow[t]{2}{*}{$\begin{array}{l}\text { Média } \\
\text { Mean }\end{array}$} & \multirow[t]{2}{*}{ CV(\%) } \\
\hline & $\begin{array}{c}\text { Controle } \\
\text { Control }\end{array}$ & $\begin{array}{l}15 \% \mathrm{FC} \\
15 \% \mathrm{FC}\end{array}$ & $\begin{array}{l}30 \% \mathrm{FC} \\
30 \% \mathrm{FC}\end{array}$ & $\begin{array}{l}15 \% \mathrm{TD} \\
15 \% \mathrm{TD}\end{array}$ & $\begin{array}{l}30 \% \mathrm{TD} \\
30 \% \mathrm{TD}\end{array}$ & & \\
\hline $\begin{array}{l}\text { PL (kg/dia) } \\
\text { MP (kg/day) }\end{array}$ & 1,759a & 1,764 a & $1,208 b$ & 1,738 a & $1,682 \mathrm{a}$ & 1,630 & 12,32 \\
\hline $\begin{array}{l}\text { PLC (kg/dia) } \\
\text { FCMP (kg/day) }\end{array}$ & 1,320 a & 1,363a & $0,960 \mathrm{~b}$ & 1,325 a & 1,273ab & 1,248 & 14,12 \\
\hline
\end{tabular}

Médias seguidas de mesma letra na linha não diferiram entre si pelo teste Tukey a 5\%.

* \% de FC ou TD no concentrado em uma relação v:c de 36:64\%.

Means followed by the same letter in a row did not differ by Tukey test at $5 \%$.

* FC or TD\% in the concentrate, using roughage:concentrate ratio of 36:64\%.

As produções de leite foram menores $(\mathrm{P}<0,05)$ em $31,32 \%$ para as dietas com $30 \%$ de inclusão de farelo de cacau em relação à dieta controle, provavelmente em razão do menor consumo de MS observado, resultando na diminuição no nível de ingestão dos nutrientes, principalmente de PB e energia.

Os teores de EE das dietas com 30\% de farelo de cacau (Tabela 2) podem ter reduzido a produção de leite, agindo como fator limitante do consumo, o que estaria de acordo com Oliveira Jr. et al. (2000b), que constataram queda linear da produção de leite de cabras recebendo dietas contendo 3,2; 4,4; 5,6 e 6,3\% de EE.

A produção de leite corrigida do tratamento com $30 \%$ de farelo de cacau só não diferiu estatisticamente $(\mathrm{P}>0,05)$ da obtida do tratamento com $30 \%$ de torta de dendê, apesar de ter apresentado valores 24,59\% menores, que também podem ser explicados pelos maiores teores de EE, que, mesmo não sendo diferentes $(\mathrm{P}>0,05)$, aproximaram dos valores da produção de leite corrigida para gordura entre os tratamentos. Resultados similares foram constata- dos por Lu (1993), que adicionou 5\% de gordura animal na dieta de cabras em lactação, e por Oliveira Jr. et al. (2000b), que utilizaram dietas isoprotéicas à base de silagem de milho e mistura concentrada com $0 ; 7 ; 14$ e $21 \%$ de substituição do farelo de soja por grão de soja, com base na MS.

\section{Conclusões}

O farelo de cacau e a torta de dendê podem substituir o concentrado à base de milho moído e farelo de soja em até 9,23 e 18,81\% da matéria seca da dieta, respectivamente, sem reduzir o consumo e a produção do leite de cabra. A inclusão de $18,47 \%$ de farelo de cacau na matéria seca da dieta de cabras afetou negativamente o consumo e a produção de leite das cabras.

\section{Literatura Citada}

AGRICULTURAL AND FOOD RESESARCH COUNCIL AFRC. Energy and protein requirements of ruminants. Wallingford: CAB International, 1993. 159p. 
CARVALHO, S.; RODRIGUES, M.T.; BRANCO, R.H. et al. Avaliação dos sistemas NRC (1981) e AFRC (1993) para caprinos no consumo de matéria seca. In: REUNIÃO ANUAL DA SOCIEDADE BRASILEIRA DE ZOOTECNIA, 39., 2002, Recife. Anais... Recife: Sociedade Brasileira de Zootecnia, 2002. CD-ROM. Nutrição de Ruminantes.

CHALUPA, W.; FERGUSON, J.D. The role of dietary fat in productivity and health of dairy cows. In: ANNUAL MEETING OF VETERINARY MEDICENE NORTH CAROLINA STATE UNIVERSITY, 1988, Raleigh. Proceedings... Wayne: American Cyanamid Company, Agricultural Division, 1988. p.36.

GONÇALVES, A.L.; LANA, R.P; RODRIGUES, M.T. et al. Padrão nictemeral do $\mathrm{pH}$ ruminal e comportamento alimentar de cabras leiteiras alimentadas com dietas contendo diferentes relações volumosos:concentrados. Revista Brasileira de Zootecnia, v.30, n.6, p.1886-1882, 2001.

INSTITUTO BRASILEIRO DE GEOGRAFIA E ESTATÍSTICA - IBGE. Produção agrícola municipal (PAM): quantidade produzida. Disponível em: www.sidra.ibge.gov.br/bda/tabela/lestabl.asp?c=1613\&z=t\&o=11. Acessado em: 08/03/2004.

LIZIEIRE, R.S.; COELHO DA SILVA, J.F.; LEÃO, M.I. et al. Níveis crescentes de proteína degradada no rúmen de cabras. 1. Efeitos sobre alguns parâmetros da fermentação ruminal. Revista da Sociedade Brasileira de Zootecnia, v.19, n.6, p.562-563, 1990.

LU, C.D. Implication of feeding isoenergetic diets containing animal fat on milk composition of Alpine does during lactation. Journal of Animal Science, v.76, p.1137-1147, 1993.

NATIONAL RESEARCH COUNCIL - NRC. Nutrient Requirements of goats: angora, dairy, and meat goats in tempera tropical countries. Washington: National Research Council, National Academy Press, 1981. v.15. 91p.

OLIVEIRA JR., R.C.; SUSIN, I.; PIRES, A.V. et al. Efeitos de níveis de grão de soja na dieta de cabras. 1. Consumo e digestibilidade dos nutrientes. In: REUNIÃO ANUAL DA SOCIEDADE BRASILEIRA DE ZOOTECNIA, 37., 2000, Viçosa, MG. Anais... Viçosa, MG: Sociedade Brasileira de Zootecnia, 2000a. CD-ROM. Nutrição de Ruminantes.

OLIVEIRA JR., R.C.; SUSIN, I.; PIRES, A.V. et al. Efeitos de níveis de grão de soja na dieta de cabras. 2 Produção e composição do leite. In: REUNIÃO ANUAL DA SOCIEDADE BRASILEIRA DE ZOOTECNIA, 37., 2000, Viçosa, MG. Anais... Viçosa, MG: Sociedade Brasileira de Zootecnia, 2000b. CD-ROM. Nutrição de Ruminantes

PALMQUIST, D.L. Suplementação de lipídeos para vacas em lactação. In: SIMPÓSIO SOBRE NUTRIÇÃO DE RUMINANTES, 6., 1989, Piracicaba. Anais... Piracicaba: Fundação de Estudos Agrários “Luis de Queiroz”, 1989. p.11-25.

PIRES, A.J.V; VIEIRAS, V.F.; SILVA, F.F.et al. Níveis de farelo de cacau (Theobrama cacao) na alimentação de bovinos. Revista Electrónica de Veterinaria, v.6, n.2, p.1-14, 2005.
RODRIGUES FILHO, J.A.; CAMARÃO, A.P.; BATISTA, H. A.M. et al. Níveis de torta de dendê em substituição ao farelo de trigo no consumo voluntário e digestibilidade de concentrados. In: REUNIÃO DA SOCIEDADE BRASILEIRA DE ZOOTECNIA, 35., 1996, Fortaleza. Anais... Fortaleza: Sociedade Brasileira de Zootecnia, 1996. p.292-293.

SILVA, D.J.; QUEIROZ, A.C. Análise de alimentos: métodos químicos e biológicos. 3.ed. Viçosa, MG: Universidade Federal de Viçosa, 2002. 235p.

SILVA, F.F.; PIRES, A.J.V.; OLIVEIRA, A.R.A. et al. Torta de dendê em dietas de bezerros leiteiros desmamados precocemente. In: REUNIÃO DA SOCIEDADE BRASILEIRA DE ZOOTECNIA, 37., 2000, Viçosa, MG. Anais... Viçosa, MG, 2000. CD-ROM. Nutrição de Ruminantes.

SILVA, J.H.; RODRIGUES, M.T.; CAMPOS, J. Desempenho de cabras leiteira recebendo dietas com diferentes relações volumoso:concentrado. Revista Brasileira de Zootecnia, v.28, n.6, p.1412-1418, 1999.

SILVA SOBRINHO, A.G.; RODRIGUES, M.T.; GARCIA, J.A. et al. Exigências nutricionais de proteína para mantença de cabras. Revista da Sociedade Brasileira de Zootecnia, v.20, n.6, p.604-613, 1991.

SKLAN, D.; ASHKENAZI, R.; BRAUN, A. et al. Fatty acids, calcium soaps of fatty acids and cottonseeds fed to high yielding cows. Journal of Dairy Science, v.75, n.9, p.2463-2472, 1992.

SNIFFEN, C.J.; Van SOEST, P.J. A net carbohydrate and protein system for evaluating cattle diets: II. Carbohydrate and protein availability. Journal of Animal Science, v.70, p.3562-3577, 1992.

SOLAIMAN, S.G.; SMOOT, Y.P.; OWENS, F.N. Inpact of EasiFlo cotonseed on feed intake, apparente digestibility, and rate of passage by goats fed a diet containing $45 \%$ hay. Journal of Animal Science, v.80, p.805-811, 2002.

UNIVERSIDADE FEDERAL DE VIÇOSA - UFV. SAEG sistema para análise estatística e genética: versão 8.0 . Viçosa: Fundação Arthur Bernardes, 1998. Apostila.

Van SOEST, P.J. Nutritional ecology of the ruminant. Cornell University. 2.ed. 1994. 476p.

WEISS, W. Energy prediction equations for ruminant. In: CORNELL NUTRITION CONFERENCE FOR FEED MANUFACTURERS, 61., 1999, Ithaca. Proceedings... Ithaca: Cornell University, 1999. p.176-185. 